\title{
Colour duplex ultrasound and simplified corporoglanular shunting procedures with and without tunnelling in contemporary management of priapism
}

\author{
Anthony J. Bella, MD; ${ }^{*}$ Tom F. Lue, $M D^{\dagger}$ \\ See related article page 304
}

I nitial determination of nonischemic versus ischemic priapism is paramount to selecting appropriate management. Although the term "low-flow" priapism was historically used, this represents a misnomer as colour duplex Doppler ultrasound (CDU) studies clearly demonstrate a complete lack of blood flow in the corpus cavernosum for compartment syndrome of the penis. Alternatively, the terms "noflow" priapism and "high-flow" priapism may be used.

As reported by Chiou and colleagues ${ }^{2}$ in this issue, CDU is increasingly used to identify the type of priapism and confirm resolution following treatment. Ischemic and nonischemic pathologies are readily distinguished (absence of flow v. cavernosal artery rupture and unregulated blood flow with blood pooling with the nonischemic type). Clinically, it is important to remember that all cases of priapism begin with influx of arterial blood and that cavernous blood gas measurement, if performed early, may be misleading.

The key to successful restoration of corporal circulation after failed nonsurgical management is a large shunt between the corpus cavernosa and either the glans, corpus spongiosum or dorsal/saphenous veins, resolving the priapistic episode and draining the tremendous flows from postischemic hyperaemia, especially in cases of prolonged priapism or failure of initial shunt procedures. ${ }^{3}$ With the exception of the Al-Ghorab shunt, other distal procedures are often too small to accommodate the increased blood flow from postischemic hyperemia, resulting in poor drainage, increased intracavernous pressure and consequent premature closure of the shunt. ${ }^{3}$ Proximal shunts may result in larger diameter fistulas but are more difficult for the occasional practitioner to perform; this is also the case for more complex distal shunts recently described. ${ }^{2,3}$

The T-Shunt technique fulfills several important criteria for primary (and salvage) surgical management in that immediate resolution of ischemic pain is achieved, a wide-area reliably patent shunt is created, the procedure is technically simple and it may, at the surgeon's choice, be performed under local anesthetic. ${ }^{3}$ Given these characteristics, the
T-shunt (with or without tunnelling, as described below) has the potential to replace all distal and proximal shunts. ${ }^{3}$

For the T-shunt, general/spinal anesthetic or penile/glans nerve block with xylocaine or bupivacaine with a 25-gauge needle may be used. As priapism usually spares the glans penis, the rigid cavernous body tips are readily palpable, and a number- 10 blade is placed vertically through the glans until it is fully within the cavernosum, staying parallel and at least $4 \mathrm{~mm}$ away from the opening of the meatus on entry (preventing urethral injury). ${ }^{3}$ The blade is rotated 90 degrees away from the urethra, followed by removal and milking of stagnant blood from the corporoglanular shunt. After confirming detumescence, the glans is sutured with an absorbable suture (the deeper spongiosal tissue is not obliterated); if there is a recurrent rigid erection, a second (bilateral) shunt is created as the tip of the corpus cavernosum is again palpable. The T-shunt should not be performed on a partially erect penis to avoid injury to the urethra. The number-10 blade T-shunt technique creates a nominal shunt surface area of $50 \mathrm{~mm}^{2}$ after scalpel rotation and removal. ${ }^{3}$ In patients with priapism lasting more than 3 days, bilateral T-shunts accompanied by insertion of a 20-Fr dilator or sounds through the glanular incision to the crus on both sides is performed, creating an intracavernous tunnel for the blood to flow from proximal to distal corpora and then via the shunt to the glans. Illustrated surgical technique and outcome publications for the T-shunt are available to the interested reader. ${ }^{3,4}$

Lue has proposed a 3 -step simplified approach for the management of prolonged ischemic priapism (Table 1).

Table 1. Treatment of ischemic priapism: a 3-step duration dependent approach

\begin{tabular}{lcl}
\hline Stage & Duration & \multicolumn{1}{c}{ Treatment } \\
\hline 1 & $<24 \mathrm{~h}$ & $\begin{array}{l}\text { Evacuation of old blood + diluted } \\
\alpha \text { adrenergic agent }\end{array}$ \\
2 & $1-2 \mathrm{~d}$ & $\begin{array}{l}\text { T-shunt } \\
3\end{array}$ \\
\hline
\end{tabular}


Recognizing the altered physiological state of priapism of greater than 3 days' duration, re-establishment of cavernosal blood circulation requires a large shunt and an intracavernous tunnel, as seen in the T-shunt or Burnett and Pierorazio's "corporal snake" manoeuvres., 3,5

Clinically, with priapism of extended duration (>36 h) and on occasion shorter timeframes, often only partial detumescence is noted after successful shunting. This is due to tissue death, edema and postischemic hyperemia. ${ }^{4}$ It is common to doubt the success of the shunt procedure in light of such a scenario afterward. Colour Doppler ultrasound can be used to differentiate recurrent ischemic priapism (no flow in the cavernous arteries) from postischemic hyperemia (high flow in the cavernous arteries), therefore avoiding unnecessary secondary procedures. ${ }^{2,3}$

Before any form of surgical management of priapism, informed consent is key as more than $50 \%$ of patients will have some form of erectile compromise due to underlying tissue changes at the time of treatment, regardless of therapeutic approach. ${ }^{4}$ However, initial results for prolonged priapism ( $>2 \mathrm{~d}$ ) from the tunnelling series by Brant and colleagues ${ }^{3}$ and Burnett and Pierorazio ${ }^{5}$ are encouraging, as return of potency (as measured by validated metrics) is markedly elevated compared with previous published series; either previously standard therapeutic options for priapism lasting more than 2 days are generally uniformly suboptimal or there is some feature of the tunnelling procedure that substantially helps in the recovery of erectile function.

\section{Competing interests: None declared.}

*Assistant Professor, Urology, and Director of Basic Urologic Research, Associate Scientist, Neuroscience, Ottawa Health Research Institute, University of Ottawa, Ottawa, Ont.; †Professor and Vice-Chairman of Urology, University of California San Francisco, Calif.

\section{References}

1. Brant WO, Bella AJ, Garcia MM, et al. Priapism: etiology, diagnosis and management. Linthicum MD 2006;25:11.

2. Chiou RK, Aggarwal H, Chiou CR. Colour Doppler ultrasound hemodynamic characteristics of patients with priapism before and after therapeutic interventions. Can Urol Assoc J 2009;4:304-11.

3. Brant WO, Garcia MM, Bella AJ, et al. T-shaped shunt and intracavernous tunneling for prolonged ischemic priapism. J Urol 2009;181:1699-705.

4. Garcia MM, Shindel AW, Lue TF. T-shunt with or without tunneling for prolonged ischemic priapism. BJU Int 2008; 102:1754-64.

5. Burnett AL, Pierorazio PM. Corporal "snake" maneuver: corporoglanular shunt surgical modification for ischemic priapism. J Sex Med 2009;6:1171-6.

Correspondence: Dr. Anthony J. Bella, Division of Urology, The Ottawa Hospital, Civic Campus, 1053 Carling Ave., Ottawa ON KIY 4EP; fax 613 761-5305; abella@ohri.ca

\section{Reprints}

\section{Bulk reprints of CUAJ articles are available in mini- mum quantities of 50}
For information or orders: Reprint Coordinator journal@cua.org

\section{Tirés à part}

\section{On peut obtenir en lots des tirés à part des articles du CUAJ (minimum de 50)}

Renseignements ou commandes : Coordonnatrice des tirés à part journal@cua.org

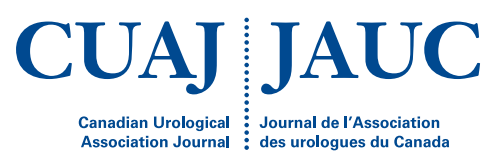

